\title{
Neighborhood Restaurant Availability and Frequency of Eating Out in Relation to Dietary Intake in Young Japanese Women
}

\author{
Kentaro MURAKAMI ${ }^{1}$, Satoshi SASAKI ${ }^{1}$, Yoshiko TAKAHASHI ${ }^{2}$, Kazuhiro UenISHI ${ }^{3}$, \\ and the Japan Dietetic Students' Study for Nutrition and Biomarkers Group \\ ${ }^{1}$ Department of Social and Preventive Epidemiology, School of Public Health, University of Tokyo, \\ Hongo 7-3-1, Bunkyo-ku, Tokyo 113-0033, Japan \\ ${ }^{2}$ Department of Health and Nutrition, School of Home Economics, Wayo Women's University, \\ Chiba 272-8533, Japan \\ ${ }^{3}$ Laboratory of Physiological Nutrition, Kagawa Nutrition University, Saitama 350-0288, Japan
}

(Received September 1, 2010)

\begin{abstract}
Summary Exposure to food service establishments is considered to encourage consumption and contribute to poorer diet quality, and hence adverse health profiles. However, empirical verification of these links remains rare, particularly in young adults and nonWestern populations. The objective of this cross-sectional study was to test the hypothesis that neighborhood restaurant availability and frequency of eating out are associated with unfavorable patterns of dietary intake and thus possibly higher body mass index (BMI) and waist circumference in young Japanese women. The subjects were 989 female Japanese dietetic students 18 to $22 \mathrm{y}$ of age. Dietary intake and frequency of eating out (i.e., consumption of commercially prepared meals) during the preceding month were assessed using a comprehensive, self-administered diet history questionnaire. Neighborhood restaurant availability was defined as the number of restaurants within a 0.5 -mile $(0.8-\mathrm{km})$ radius of residence (i.e., full-service restaurants, limited-service restaurants, and cafeterias). Increasing frequency of eating out was associated with higher intake of meat, confectionery and bread, and dietary fat, lower intake of fruit and vegetables, rice, and dietary fiber, and higher dietary energy density. However, neighborhood restaurant availability was not associated with either the frequency of eating out or any of the dietary variables examined. Further, frequency of eating out and neighborhood restaurant availability were not associated with BMI or waist circumference. In conclusion, although frequency of eating out was positively associated with unfavorable dietary intake patterns in a group of young Japanese women, neighborhood restaurant availability was not associated with frequency of eating out or dietary intake.
\end{abstract}

Key Words neighborhood, restaurant availability, eating out, diet, epidemiology

Living conditions are shaped by characteristics of the residential environment; therefore, neighborhood characteristics may have some impact on lifestyle factors such as dietary habits and, hence, on health status such as obesity, beyond any effect of the characteristics of the individual (1). Growing recognition of the importance of diet on health has been accompanied by increasing attention to factors associated with access to healthy foods. In fact, several studies have shown that the neighborhood food service environment (e.g., better access to fast-food outlets) is associated with an unfavorable dietary pattern (e.g., lower consumption of fruit and vegetables) $(2,3)$ and health status (e.g., higher prevalence of obesity) (4-7), while other studies have not supported the potential influence of neighborhood food service establishments on $\operatorname{diet}(8,9)$ and health $(9$, $10)$ in the expected direction. In a very recent study in Australia, the variety of fast food restaurants in neighborhoods (i.e., the number of different fast food chains

E-mail: kenmrkm@m.u-tokyo.ac.jp within $3 \mathrm{~km}$ of road network distance), but not density (i.e., the number of fast food restaurants) or proximity (i.e., the road network distance to the closest fast food restaurant), was independently associated with increasing fast food purchasing (11). However, empirical verification of these links remains scarce. Further, all studies on this topic have been conducted in Western countries, and information among young adult populations is lacking. Moreover, most of these studies focused on fruit and vegetable intake and gave little or no consideration to other food groups $(3,9)$, and only a few used a validated dietary assessment instrument $(2,8)$.

The purpose of this cross-sectional study in a group of young Japanese women was to examine the associations among neighborhood restaurant availability, frequency of eating out, dietary intake, as assessed using a validated, comprehensive self-administered diet history questionnaire (DHQ) (12-15), body mass index (BMI), and waist circumference. Exposure to food service establishments is considered to encourage consumption and contribute to poorer diet quality, and hence adverse 
health profiles (2-11). We thus hypothesized that neighborhood restaurant availability and frequency of eating out are associated with unfavorable patterns of dietary intake and thus possibly higher body mass index (BMI) and waist circumference. Given differences in dietary habits and neighborhood characteristics between countries, the influence of neighborhood characteristics on diet and health might also differ between countries. We speculated that several background characteristics specific to Japan concerning diet (e.g., high intake of rice and low intake of fat) (16), food environment (e.g., high density of a wide variety of stores) (17), and health status (e.g., low BMI) (16), compared with Western countries such as the USA (e.g., high fat consumption, low density of stores, and high BMI), would provide additional insights into the influence of local food environment on individual diet. Investigation in young Japanese women would also be important, given the widespread eating out habits in young compared with older women in Japan (40\% of women 15 to $29 \mathrm{y}$ of age and $20 \%$ of women $\geq 30 \mathrm{y}$ of age eating out $\geq 2$ times/wk) (16).

\section{MATERIALS AND METHODS}

Study sample. The present study was based on data from the Japan Dietetic Students' Study for Nutrition and Biomarkers, a cross-sectional multi-center survey conducted from February to March 2006 and from January to March 2007 among female dietetic students from 15 institutions in Japan. A total of 1,176 Japanese women took part. A detailed description of the study design and survey procedure has been published elsewhere (18-20). Written informed consent was obtained from each participant, and also from a parent for participants younger than $20 \mathrm{y}$ of age. The present study was conducted according to the guidelines laid down in the Declaration of Helsinki, and the study protocol was approved by the Ethics Committee of the National Institute of Health and Nutrition, Japan.

Japan is a country consisting of four main islands, running from north to south: Hokkaido (population density 67 persons $/ \mathrm{km}^{2}$ ), Honshu [the main and largest island, which is usually divided into six areas: Tohoku (144 persons $/ \mathrm{km}^{2}$ ), Kanto (878 persons $/ \mathrm{km}^{2}$ ), Hokuriku (219 persons $/ \mathrm{km}^{2}$ ), Tokai (507 persons $/ \mathrm{km}^{2}$ ), Kinki (756 persons $/ \mathrm{km}^{2}$ ), and Chugoku (219 persons/ $\left.\mathrm{km}^{2}\right)$ ], Shikoku (218 persons $/ \mathrm{km}^{2}$ ), and Kyushu (332 persons $/ \mathrm{km}^{2}$ ) (21). In Japan, the 2,372 municipalities consist of 164 wards (i.e., metropolitan areas), 736 cities, 1,178 towns, and 294 villages (21).

For the present analysis, we selected women 18 to $22 \mathrm{y}$ of age $(n=1,154)$. We then excluded women not providing sufficient information on their home address $(n=164)$, those who reported extremely low or high energy intake $(<500$ or $>4,000 \mathrm{kcal} / \mathrm{d}, n=3)$, and those with missing information on the variables used $(n=1)$. As some participants were in $>1$ exclusion category, the final analysis sample comprised 989 women, residing in a wide geographical range of areas in Japan (i.e., 25 (of 47) prefectures, 283 (of 2,372) municipali- ties, and 703 (of 386,877) 1-km mesh-blocks).

Dietary intake. Dietary habits during the preceding month were assessed using a comprehensive selfadministered DHQ (12-15). Responses to the DHQ, as well as to a lifestyle questionnaire, were checked at least twice for completeness. When necessary, forms were reviewed with the subject to ensure the clarity of answers. Details of the DHQ's structure, calculation of dietary intake, and validity for commonly studied nutritional factors have been published elsewhere (12-15). Briefly, the DHQ is a structured 16-page questionnaire which asks about the consumption frequency and portion size of selected foods commonly consumed in Japan as well as general dietary behavior and usual cooking methods (12). Estimates of daily intake for foods (150 items in total), selected nutrients (i.e., dietary fat and fiber), and energy were calculated using an ad hoc computer algorithm for the DHQ $(12,15)$ based on the Standard Tables of Food Composition in Japan (22). In the present study, the following five food groups were considered: meat, fish, fruit and vegetables, confectionery and bread, and rice (categorization of food groups has been published elsewhere) (23). To minimize the influence of dietary misreporting, an ongoing controversy in studies that collect dietary information using self-report instruments (24), intake of food groups and nutrients was energy-adjusted using the density method (\% of energy for dietary fat and g/1,000 kcal for dietary fiber and food groups). As a measure of diet quality, dietary energy density $(\mathrm{kcal} / \mathrm{g})$ was calculated based on foods only (128 items; excluding all caloric and non-caloric beverages, including drinking water) (18). In a previous study of 92 women 31 to $69 \mathrm{y}$ of age, Pearson's correlation coefficients between the DHQ and 16-d weighed dietary records were 0.66 for meat, 0.55 for fish and shellfish, 0.51 for fruit and vegetables, 0.51 for confectionery and bread, 0.64 for rice, 0.60 for fat, 0.71 for dietary fiber, and 0.52 for dietary energy density $(18,20,25)$, suggesting satisfactory validity of the DHQ in terms of these dietary variables.

BMI and waist circumference. Body height was measured (once for each person) to the nearest $0.1 \mathrm{~cm}$ while the subject was standing without shoes, and body weight to the nearest $0.1 \mathrm{~kg}$ while the subject was wearing lightweight indoor clothing. BMI was calculated as body weight $(\mathrm{kg})$ divided by the square of body height $(\mathrm{m})$. Waist circumference was measured to the nearest $0.1 \mathrm{~cm}$ at the level of the umbilicus. The measurement was taken at the end of a normal respiration while the subject was standing erect and with the arms at the side and the feet together.

Frequency of eating out. As part of the DHQ, participants were asked to report the frequency of eating out (i.e., consuming commercially prepared meals) during the preceding month. Eight response options were provided: $\geq 2$ times/d (17.5 times/wk for a continuous variable), 1 time/d (7 times/wk), 4-6 times/wk (5 times/wk), 2-3 times/wk (2.5 times/wk), 1 time/wk (1 time/wk), 2-3 times/mo (0.58 times/wk), 1 time/mo (0.23 times/wk), and never (0 time/wk). 
Neighborhood restaurant availability. Neighborhood restaurant availability was defined as the number of restaurants within a 0.5 -mile $(0.8-\mathrm{km})$ radius of residence. In accordance with the Japan Standardized Industrial Classification (26), the following three types of restaurants were selected for investigation: full-service restaurants, limited-service restaurants (e.g., fast-food restaurants and pizza delivery shops), and cafeterias.

Due to the unavailability of raw data collected by governments in Japan (except to civil servants in relevant departments) and widespread distribution of our participants, neighborhood restaurant availability was assessed based on a commercial electronic database of telephone business directories (version 13, business special, 2008, Nippon Software Service Inc, Tokyo, Japan). This database consists of information appearing in all telephone business directories published in Japan as of October 2007, including data on telephone and fax numbers, (store) name, and street address. The street addresses in the database were geocoded by exact address matching, along with participants' home addresses as reported in the lifestyle questionnaire. For data identified within a 0.5 -mile $(0.8-\mathrm{km})$ radius of a participant's home, categorization of restaurants was systematically made based on name recognition by one of us, after the exclusion of duplicate data (i.e., same telephone numbers and same names). Restaurant (or store) names that were vague were assigned to a category by one of us after checking the business pages of the online telephone business directory (http://phonebook.yahoo.co.jp/) or, in some cases, company and community websites. Finally, the number of restaurants of these three types within a 0.5 -mile $(0.8-\mathrm{km})$ radius of residence was calculated for each participant.

Because neighborhood availability of the three types of restaurants was positively correlated (Spearman's correlation coefficients: $0.54-0.83$ ) and the results based on these three measures were similar, we present here the results based on neighborhood availability of the three types of restaurants combined only.

Other variables. Based on the reported home address, each participant was grouped into one of six regions (Hokkaido and Tohoku; Kanto; Hokuriku and Tokai; Kinki; Chugoku and Shikoku; and Kyushu) and into one of three municipality levels (ward (i.e., metropolitan area); city; and town and village). The participant was also grouped into one of four institution types (4-y private, 2-y private, 4-y public, and 2-y public) based on the institution she attended and into one of three living statuses (living with family, living alone, and living with others), as self-reported in the lifestyle questionnaire. Current smoking (yes or no) and current alcohol drinking (yes or no, because of an extremely low mean intake of alcohol: $0.5 \%$ of energy) were also self-reported in the lifestyle questionnaire and DHQ, respectively. Physical activity was computed as the average metabolic equivalents-hours score per day (27) on the basis of the frequency and duration of five activities (sleeping, highand moderate-intensity activities, walking, and sedentary activities) over the preceding month, as reported in
Table 1. Basic characteristics of 989 Japanese women 18 to 22 y of age. ${ }^{1}$

\begin{tabular}{|c|c|}
\hline Variable & Value \\
\hline Age (y) & $19.6 \pm 1.0$ \\
\hline Body height (cm) & $158.2 \pm 5.5$ \\
\hline Body weight (kg) & $53.6 \pm 7.8$ \\
\hline Body mass index $\left(\mathrm{kg} / \mathrm{m}^{2}\right)$ & $21.4 \pm 2.8$ \\
\hline Waist circumference $(\mathrm{cm})$ & $72.8 \pm 7.1$ \\
\hline \multicolumn{2}{|l|}{ Survey year } \\
\hline 2006 & 41.7 \\
\hline 2007 & 58.3 \\
\hline \multicolumn{2}{|l|}{ Region } \\
\hline Hokkaido and Tohoku & 2.5 \\
\hline Kanto & 56.1 \\
\hline Hokuriku and Tokai & 10.8 \\
\hline Kinki & 11.3 \\
\hline Chugoku and Shikoku & 2.9 \\
\hline Kyushu & 16.3 \\
\hline \multicolumn{2}{|l|}{ Municipality level } \\
\hline Ward & 17.2 \\
\hline City & 76.3 \\
\hline Town and village & 6.5 \\
\hline \multicolumn{2}{|l|}{ Institution type } \\
\hline 4-y private & 70.8 \\
\hline 2-y private & 6.0 \\
\hline 4-y public & 14.3 \\
\hline $2-y$ public & 9.0 \\
\hline \multicolumn{2}{|l|}{ Living status } \\
\hline Living with family & 64.6 \\
\hline Living alone & 32.2 \\
\hline Living with others & 3.2 \\
\hline Smoker & 2.4 \\
\hline Alcohol drinker & 40.9 \\
\hline $\begin{array}{l}\text { Physical activity } \\
\text { (total metabolic equivalents-h/d) }\end{array}$ & $34.0 \pm 3.1$ \\
\hline Frequency of eating out (times/wk) & $2.9 \pm 2.7$ \\
\hline $\begin{array}{l}\text { Neighborhood restaurant availability } \\
\text { (number of restaurants within a } 0.5 \text {-mile } \\
(0.8-\mathrm{km}) \text { radius of residence) }\end{array}$ & $35(14-62)$ \\
\hline Total energy intake (kcal/d) & $1,777 \pm 454$ \\
\hline \multicolumn{2}{|l|}{ Food intake (g/1,000 kcal) } \\
\hline Meat & $33.8 \pm 16.8$ \\
\hline Fish & $28.5 \pm 15.3$ \\
\hline Fruit and vegetables & $180.4 \pm 93.3$ \\
\hline Confectionery and bread & $69.3 \pm 32.1$ \\
\hline Rice & $156.6 \pm 63.7$ \\
\hline \multicolumn{2}{|l|}{ Nutrient intake } \\
\hline Dietary fat (\% of energy) & $29.3 \pm 5.2$ \\
\hline Dietary fiber (g/1,000 kcal) & $6.8 \pm 1.9$ \\
\hline Dietary energy density (kcal/g) & $1.41 \pm 0.23$ \\
\hline
\end{tabular}

${ }^{1}$ Values are means $\pm S D$, percentages of participants, or medians (interquartile ranges).

the lifestyle questionnaire.

Statistical analyses. All statistical analyses were performed using SAS statistical software (version 9.1, 2003, SAS Institute Inc, Cary, NC, USA). Descriptive data are shown as means and standard deviations, percentages of participants, or medians and interquartile ranges. Using the PROC GLM procedure, linear regression models were constructed to examine the associa- 
Table 2. Selected characteristics of 989 Japanese women 18 to $22 \mathrm{y}$ of age according to approximate quartile categories of frequency of eating out and neighborhood restaurant availability (number of restaurants within a $0.5-\mathrm{mile}(0.8-\mathrm{km})$ radius of residence). ${ }^{1}$

\begin{tabular}{|c|c|c|c|c|c|c|}
\hline \multirow{2}{*}{ Variable } & \multicolumn{3}{|c|}{ Frequency of eating out } & \multicolumn{3}{|c|}{ Neighborhood restaurant availability } \\
\hline & $\begin{array}{c}\text { Quartile } 1 \\
\text { (lowest; } n=203 \text { ) }\end{array}$ & $\begin{array}{c}\text { Quartile } 4 \\
\text { (highest; } n=301 \text { ) }\end{array}$ & $p^{2}$ & $\begin{array}{c}\text { Quartile } 1 \\
\text { (lowest; } n=253 \text { ) }\end{array}$ & $\begin{array}{c}\text { Quartile } 4 \\
\text { (highest; } n=246 \text { ) }\end{array}$ & $p^{2}$ \\
\hline Survey year & & & 0.008 & & & 0.18 \\
\hline 2006 & 45.8 & 33.9 & & 38.3 & 42.7 & \\
\hline 2007 & 54.2 & 66.1 & & 61.7 & 57.3 & \\
\hline Region & & & 0.49 & & & $<0.0001$ \\
\hline Hokkaido and Tohoku & 1.5 & 1.7 & & 5.1 & 1.2 & \\
\hline Kanto & 56.7 & 56.8 & & 37.6 & 73.2 & \\
\hline Hokuriku and Tokai & 15.3 & 9.0 & & 17.8 & 3.3 & \\
\hline Kinki & 9.4 & 13.3 & & 11.9 & 11.4 & \\
\hline Chugoku and Shikoku & 3.5 & 4.0 & & 3.2 & 0.8 & \\
\hline Kyushu & 13.8 & 15.3 & & 24.5 & 10.2 & \\
\hline Municipality level & & & 0.008 & & & $<0.0001$ \\
\hline Ward & 14.3 & 21.3 & & 3.6 & 39.4 & \\
\hline City & 77.3 & 74.1 & & 79.1 & 60.6 & \\
\hline Town and village & 8.4 & 4.7 & & 17.4 & 0 & \\
\hline Institution type & & & 0.99 & & & $<0.0001$ \\
\hline 4-y private & 69.5 & 68.8 & & 60.9 & 84.2 & \\
\hline 2-y private & 8.9 & 4.3 & & 13.8 & 2.0 & \\
\hline 4-y public & 6.9 & 19.9 & & 15.0 & 10.2 & \\
\hline $2-y$ public & 14.8 & 7.0 & & 10.3 & 3.7 & \\
\hline Living status & & & $<0.0001$ & & & $<0.0001$ \\
\hline Living with family & 76.4 & 51.5 & & 91.3 & 54.1 & \\
\hline Living alone & 19.7 & 44.5 & & 7.5 & 40.2 & \\
\hline Living with others & 3.9 & 4.0 & & 1.2 & 5.7 & \\
\hline Smoker & 1.0 & 3.3 & 0.33 & 2.0 & 1.6 & 0.73 \\
\hline Alcohol drinker & 31.5 & 42.9 & 0.002 & 36.0 & 41.1 & 0.24 \\
\hline $\begin{array}{l}\text { Physical activity (total } \\
\text { metabolic equivalents-h/d) }\end{array}$ & 34.0 & 34.3 & 0.047 & 34.1 & 34.0 & 0.48 \\
\hline
\end{tabular}

${ }^{1}$ Values are percentages of participants except for physical activity (values are means). Data for quartiles 2 and 3 are not shown for simplicity.

${ }^{2}$ A Mantel-Haenszel chi-square test was used except for physical activity (a linear trend test was used).

tion of frequency of eating out with dietary intake, BMI, and waist circumference and of neighborhood restaurant availability with frequency of eating out, dietary intake, BMI, and waist circumference. For analyses, participants were categorized into approximate quartiles according to frequency of eating out and neighborhood restaurant availability. Multivariate-adjusted mean values (with standard errors) of dietary intake, BMI, waist circumference, and frequency of eating out were calculated by the approximate quartiles. Potential confounding factors included in the multivariate models were survey year, geographic variables, i.e., region and municipality level, household socioeconomic status variables, i.e., institution type and living status, and lifestyle variables, i.e., smoking, alcohol drinking, and physical activity (continuous) $(18-20,23,25,28)$. We tested for linear trends with increasing levels of frequency of eating out and neighborhood restaurant availability by assigning each participant the median value for the category and modeling this value as a continuous variable. All reported $p$ values are 2-tailed, and $p$ values of $<0.05$ were considered statistically significant.

\section{RESULTS}

Basic characteristics of participants are shown in Table 1. Mean BMI was 21.4 (SD: 2.8 ) $\mathrm{kg} / \mathrm{m}^{2}$ and mean waist circumference was 72.8 (SD: 7.1) $\mathrm{cm}$. Median number of restaurants in neighborhoods (i.e., neighborhood restaurant availability) was 35 (interquartile range: 14-62). Mean value of frequency of eating out was 2.9 (SD: 2.7) times/wk.

Potential confounding factors according to approximate quartile category of the frequency of eating out are shown in Table 2. Frequency of eating out was associated with survey year, municipality level, living status, alcohol drinking, and physical activity. The higher quartiles of frequency of eating out included more participants in the 2007 survey; more participants living in wards and fewer living in villages; more participants living alone and fewer living with family; more alcohol drinkers; and more participants with higher physical activity.

Potential confounding factors according to approximate quartile category of neighborhood restaurant 
Table 3. Dietary characteristics, body mass index, and waist circumference of 989 Japanese women 18 to 22 y of age according to approximate quartile category of frequency of eating out. ${ }^{1}$

\begin{tabular}{|c|c|c|c|c|c|}
\hline Variable & $\begin{array}{c}\text { Quartile } 1 \\
\text { (lowest; } n=203 \text { ) }\end{array}$ & $\begin{array}{l}\text { Quartile } 2 \\
(n=195)\end{array}$ & $\begin{array}{l}\text { Quartile } 3 \\
(n=290)\end{array}$ & $\begin{array}{c}\text { Quartile } 4 \\
\text { (highest; } n=301 \text { ) }\end{array}$ & $p^{2}$ \\
\hline Frequency of eating out (times/wk) & $0.6(0-0.6)$ & $1.0(1.0)$ & $2.5(2.5)$ & $5.0(5.0-17.5)$ & - \\
\hline \multicolumn{6}{|l|}{ Food intake $(\mathrm{g} / 1,000 \mathrm{kcal})^{3}$} \\
\hline Meat & $31.2 \pm 1.2$ & $32.7 \pm 1.2$ & $35.2 \pm 0.9$ & $34.9 \pm 0.9$ & 0.02 \\
\hline Fish & $28.2 \pm 1.0$ & $29.6 \pm 1.0$ & $28.6 \pm 0.8$ & $27.9 \pm 0.8$ & 0.42 \\
\hline Fruit and vegetables & $186.7 \pm 6.6$ & $189.3 \pm 6.6$ & $178.3 \pm 5.4$ & $172.5 \pm 5.4$ & 0.04 \\
\hline Confectionery and bread & $60.0 \pm 2.2$ & $66.1 \pm 2.2$ & $70.6 \pm 1.8$ & $76.3 \pm 1.8$ & $<0.0001$ \\
\hline Rice & $179.6 \pm 4.4$ & $162.7 \pm 4.4$ & $150.2 \pm 3.6$ & $143.3 \pm 3.6$ & $<0.0001$ \\
\hline \multicolumn{6}{|l|}{ Nutrient intake $\mathrm{e}^{3}$} \\
\hline Dietary fat (\% of energy) & $27.7 \pm 0.4$ & $28.7 \pm 0.4$ & $29.9 \pm 0.3$ & $30.1 \pm 0.3$ & $<0.0001$ \\
\hline Dietary fiber (g/1,000 kcal) & $7.1 \pm 0.1$ & $7.1 \pm 0.1$ & $6.8 \pm 0.1$ & $6.5 \pm 0.1$ & $<0.0001$ \\
\hline Dietary energy density $(\mathrm{kcal} / \mathrm{g})^{3}$ & $1.36 \pm 0.02$ & $1.38 \pm 0.02$ & $1.42 \pm 0.01$ & $1.46 \pm 0.01$ & $<0.0001$ \\
\hline Body mass index ${ }^{3}$ & $21.2 \pm 0.2$ & $21.9 \pm 0.2$ & $21.3 \pm 0.2$ & $21.2 \pm 0.2$ & 0.26 \\
\hline Waist circumference ${ }^{3}$ & $72.0 \pm 0.5$ & $73.9 \pm 0.5$ & $72.7 \pm 0.4$ & $72.8 \pm 0.4$ & 0.89 \\
\hline
\end{tabular}

${ }^{1}$ Values are medians (ranges) for frequency of eating out or means \pm SE for dietary characteristics, body mass index, and waist circumference.

${ }^{2}$ A linear trend test was used with the median value in each quartile category as a continuous variable in linear regression.

${ }^{3}$ Adjusted for survey year (2006 and 2007), region (Hokkaido and Tohoku; Kanto; Hokuriku and Tokai; Kinki; Chugoku and Shikoku; and Kyushu), municipality level (ward; city; and town and village), institution type (4-y private, 2-y private, 4-y public, and 2-y public), living status (living with family, living alone, and living with others), smoking (yes or no), alcohol drinking (yes or no), and physical activity (total metabolic equivalents-h/d, continuous).

Table 4. Frequency of eating out, dietary characteristics, body mass index, and waist circumference of 989 Japanese women 18 to $22 \mathrm{y}$ of age according to approximate quartile category of neighborhood restaurant availability (number of restaurants within a 0.5 -mile $(0.8-\mathrm{km})$ radius of residence $){ }^{1}$

\begin{tabular}{|c|c|c|c|c|c|}
\hline Variable & $\begin{array}{c}\text { Quartile } 1 \\
\text { (lowest; } n=253 \text { ) }\end{array}$ & $\begin{array}{l}\text { Quartile } 2 \\
(n=240)\end{array}$ & $\begin{array}{l}\text { Quartile } 3 \\
(n=250)\end{array}$ & $\begin{array}{c}\text { Quartile } 4 \\
\text { (highest; } n=246 \text { ) }\end{array}$ & $p^{2}$ \\
\hline Neighborhood restaurant availability & $4(0-14)$ & $24(15-34)$ & $48(35-62)$ & $83(63-927)$ & - \\
\hline Frequency of eating out (times/wk $)^{3}$ & $3.0 \pm 0.2$ & $3.1 \pm 0.2$ & $2.8 \pm 0.2$ & $2.7 \pm 0.2$ & 0.12 \\
\hline \multicolumn{6}{|l|}{ Food intake $(\mathrm{g} / 1,000 \mathrm{kcal})^{3}$} \\
\hline Meat & $34.4 \pm 1.2$ & $35.5 \pm 1.1$ & $33.2 \pm 1.1$ & $32.1 \pm 1.1$ & 0.10 \\
\hline Fish & $27.8 \pm 1.0$ & $29.6 \pm 0.9$ & $27.9 \pm 0.9$ & $28.8 \pm 1.0$ & 0.52 \\
\hline Fruit and vegetables & $179.3 \pm 6.7$ & $182.9 \pm 6.0$ & $179.2 \pm 6.1$ & $180.3 \pm 6.5$ & 0.77 \\
\hline Confectionery and bread & $64.7 \pm 2.3$ & $68.0 \pm 2.1$ & $73.9 \pm 2.1$ & $70.5 \pm 2.2$ & 0.14 \\
\hline Rice & $160.7 \pm 4.5$ & $157.4 \pm 4.1$ & $154.9 \pm 4.1$ & $153.2 \pm 4.4$ & 0.22 \\
\hline \multicolumn{6}{|l|}{ Nutrient intake $^{3}$} \\
\hline Dietary fat (\% of energy) & $29.6 \pm 0.4$ & $29.8 \pm 0.3$ & $28.8 \pm 0.3$ & $28.9 \pm 0.4$ & 0.16 \\
\hline Dietary fiber (g/1,000 kcal) & $6.9 \pm 0.1$ & $6.8 \pm 0.1$ & $6.7 \pm 0.1$ & $6.9 \pm 0.1$ & 0.91 \\
\hline Dietary energy density $(\mathrm{kcal} / \mathrm{g})^{3}$ & $1.39 \pm 0.02$ & $1.40 \pm 0.02$ & $1.43 \pm 0.02$ & $1.41 \pm 0.02$ & 0.58 \\
\hline Body mass index ${ }^{3}$ & $21.4 \pm 0.2$ & $21.5 \pm 0.2$ & $21.2 \pm 0.2$ & $21.3 \pm 0.2$ & 0.48 \\
\hline Waist circumference ${ }^{3}$ & $72.7 \pm 0.5$ & $72.7 \pm 0.5$ & $72.7 \pm 0.5$ & $73.1 \pm 0.5$ & 0.79 \\
\hline
\end{tabular}

\footnotetext{
${ }^{1}$ Values are medians (ranges) for neighborhood restaurant availability or means \pm SE for frequency of eating out, dietary characteristics, body mass index, and waist circumference.

${ }^{2}$ A linear trend test was used with the median value in each quartile category as a continuous variable in linear regression. ${ }^{3}$ Adjusted for survey year (2006 and 2007), region (Hokkaido and Tohoku; Kanto; Hokuriku and Tokai; Kinki; Chugoku and Shikoku; and Kyushu), municipality level (ward; city; and town and village), institution type (4-y private, 2-y private, 4-y public, and 2-y public), living status (living with family, living alone, and living with others), smoking (yes or no), alcohol drinking (yes or no), and physical activity (total metabolic equivalents-h/d, continuous).
}

availability are also shown in Table 2. Neighborhood restaurant availability was associated with region, municipality level, institution type, and living status. The higher quartiles of neighborhood restaurant availability included more participants living in Kanto and fewer living in Hokkaido and Tohoku, Hokuriku and
Tokai, and Kyushu; more participants living in wards and fewer living in villages; more participants attending 4-y private institutions and fewer attending 2-y private and 2-y public institutions; and more participants living alone and fewer living with family.

Dietary characteristics, BMI, and waist circumfer- 
ence according to approximate quartile category of frequency of eating out are shown in Table 3. After adjustment for potential confounding factors, higher frequency of eating out was associated with higher intake of meat, confectionery and bread, and dietary fat and lower intake of fruit and vegetables, rice, and dietary fiber. Frequency of eating out was also associated positively with dietary energy density. Conversely, no association was seen between frequency of eating out and BMI or waist circumference.

Frequency of eating out, dietary characteristics, BMI, and waist circumference according to approximate quartile category of neighborhood restaurant availability are shown in Table 4 . After adjustment for potential confounding factors, neighborhood restaurant availability was not associated with frequency of eating out. Further, there was no association between neighborhood restaurant availability and dietary or anthropometric measures examined.

\section{DISCUSSION}

In this cross-sectional study of a group of young Japanese women, we found that frequency of eating out was positively associated with unfavorable dietary intake patterns including higher intake of dietary fat, lower intake of fruit and vegetables and dietary fiber, and higher dietary energy density. However, neighborhood restaurant availability was not associated with the frequency of eating out or dietary intake. Additionally, both frequency and neighborhood restaurant availability were not associated with BMI or waist circumference. Thus, our hypothesis was partly supported by the present findings. To our knowledge, this is the first study to investigate the association between frequency of eating out, dietary intake, BMI, waist circumference, and neighborhood restaurant availability in young Japanese women.

In this study, frequency of eating out was associated with a poorer dietary intake, including higher energy density, a variable significantly associated with BMI and waist circumference in this population (18). Previous studies have consistently shown the unfavorable influence of eating out on dietary intake $(2,29-32)$. In contrast, we found no association between frequency of eating out and BMI or waist circumference. While some studies have shown a positive association between eating out and obesity $(7,31,33-35)$, others have not (30, 32). In our lean population at least, the effects of eating out on diet quality may have been too small to cause changes in BMI or waist circumference.

We found no association between neighborhood restaurant availability and frequency of eating out, and (hence) no association with dietary intake, BMI, or waist circumference. Similarly, no association between neighborhood availability and eating out has been seen in several other studies $(7,36)$. In the present population at least, other factors rather than availability may strongly influence eating-out behavior, such as knowledge and cost, although Japan has long been shown to have lower inequality in individual socioeconomic sta- tus than other developed countries (37). However, our results are based on a highly selected population, and thus are not likely to extrapolate to the general Japanese population, although with regard to the intake of energy and fat at least, mean values in the present study (1,777 kcal/d and $29.3 \%$ of energy, respectively) were reasonably comparable to those of a representative sample of Japanese women 18 to $29 \mathrm{y}$ of age $(1,685$ $\mathrm{kcal} / \mathrm{d}$ and $28.9 \%$ of energy, respectively) (16). The participants were selected female dietetic students, and owing to the recruitment procedure used the response rate could not be precisely determined, although the approximate rate was $56 \%$. These elements of the design may have produced recruitment bias. In addition, one would expect the present food/nutrition-oriented population to show less influence from the environment on behavior than the average population. Thus, given the present findings that under conditions of continuous education about food and nutrition, there is no relationship between proximity of restaurants and dietary intake, it would be expected that the influence of neighborhood restaurants would be greater in other populations. Alternatively, neighborhood availability may not necessarily be associated with intake in Japanese, considering the low frequency of eating out in general $(69 \%$ of people eating out $<2$ times/wk (16) and $20 \%$ of total food expenditure for eating out (21)).

Several limitations of the present study warrant mention. First, mainly because of the unavailability of government-collected data on food service establishments, we relied on a commercial database of telephone business directories to estimate neighborhood restaurant availability. Use of telephone directories may be problematic: the same restaurant may be listed several times under different names, addresses may be omitted or incorrect, and restaurants may be listed even after they have moved or closed (38). Categorization of restaurants was based on name recognition, and made with the supplemental information obtained on websites. There is thus likely to be error in the categorization of restaurants, although these procedures were conducted by one of us to reduce biases possibly occurring when different raters were involved, and any errors in the assessment of neighborhood restaurant availability should be theoretically independent of errors in dietary intake and anthropometric measures of participants.

Second, we did not have information on where participants actually ate out. As such our exposure variable is only a proxy for the neighborhood food environment. Third, we used an arbitrary unit (i.e., 0.5-mile $(0.8-\mathrm{km})$ radius of residence) as an approximation of neighborhood, but these units may not represent the area of actual relevance to the eating out habits of a particular individual. For example, reliance on the neighborhood environment for eating may differ by other factors such as transportation use, information on which was not available in the present study. Fourth, the number and type of restaurants used as proxies for availability may be a limitation; and more specific information regarding the types and costs of foods sold at 
these establishments may have been useful. Fifth, because data for restaurants (2007) and dietary and anthropometric variables (2006 and 2007) were collected at different times, the present study had to be based on the assumption that the food environment remained constant between 2006 and 2007.

Sixth, we used a self-administered semiquantitative dietary assessment questionnaire for dietary data collection. Although this questionnaire has been validated $(12-15,18,20,25)$, and energy-adjusted values of dietary intake were used to minimize the influence of measurement errors derived from self-reported dietary behavior (24), actual dietary habits were not observed. The assessment of frequency of eating out was similarly based on self-reporting. The results should thus be interpreted with caution. Seventh, we were unable to control for other factors that may influence individual dietary choices, and these may also be associated with the neighborhood food environment (e.g., personal food preferences). Finally, the cross-sectional nature of the study hampers the drawing of any conclusions on causal inferences among eating out and neighborhood restaurant availability, and dietary intake, BMI, and waist circumference.

To conclude, in this cross-sectional study of a group of young Japanese women, frequency of eating out was positively associated with unfavorable dietary intake patterns, including higher intake of dietary fat, lower intake of fruit and vegetables and dietary fiber, and higher dietary energy density. However, no association was seen between neighborhood restaurant availability and frequency of eating out or dietary intake. Further, frequency of eating out and neighborhood restaurant availability were not associated with BMI or waist circumference. The local food environment may not necessarily be associated with dietary intake and health status in Japanese settings. Our findings from a selected population should be confirmed in a more representative sample of the Japanese population.

\section{Acknowledgments}

This study was supported by Grants-in-Aid for Young Scientists (B) from the Ministry of Education, Culture, Sports, Science and Technology of Japan (no. 21700750). None of the authors had any personal or financial conflict of interest to declare.

Other members of the Japan Dietetic Students' Study for Nutrition and Biomarkers Group are as follows: Mitsuyo Yamasaki, Yuko Hisatomi, Junko Soezima, and Kazumi Takedomi (Nishikyushu University); Toshiyuki Kohri and Naoko Kaba (Kinki University); Etsuko Uneoka (Otemae College of Nutrition); Hitomi Hayabuchi and Yoko Umeki (Fukuoka Women's University); Keiko Baba and Maiko Suzuki (Mie Chukyo University Junior College); Reiko Watanabe and Kanako Muramatsu (University of Niigata Prefecture); Kazuko Ohki, Seigo Shiga, Hidemichi Ebisawa, and Masako Fuwa (Showa Women's University); Tomoko Watanabe, Ayuho Suzuki, and Fumiyo Kudo (Chiba Prefectural
University of Health Science); Katsumi Shibata, Tsutomu Fukuwatari, and Junko Hirose (The University of Shiga Prefecture); Toru Takahashi and Masako Kato (Mimasaka University); Toshinao Goda and Yoko Ichikawa (University of Shizuoka); Junko Suzuki, Yoko Niida, Satomi Morohashi, Chiaki Shimizu, and Naomi Takeuchi (Hokkaido Bunkyo University); Jun Oka and Tomoko Ide (Tokyo Kasei University); and Yoshiko Sugiyama and Mika Furuki (Minamikyushu University).

\section{REFERENCES}

1) Giskes K, Kamphuis CBM, van Lenthe FJ, Kremers S, Droomers M, Brug J. 2007. An systematic review of associations between environmental factors, energy and fat intakes among adults: is there evidence for environments that encourage obesogenic dietary intakes? Public Health Nutr 10: 1005-1017.

2) Moore LV, Diez Roux AV, Nettleton JA, Jacobs DR, Franco M. 2009. Fast-food consumption, diet quality, and neighborhood exposure to fast food. The Multi-Ethnic Study of Atherosclerosis. Am J Epidemiol 170: 2936.

3) Timperio A, Ball K, Roberts R, Campbell K, Andrianopoulos N, Crawford D. 2008. Children's fruit and vegetable intake: Associations with the neighbourhood food environment. Prev Med 46: 331-335.

4) Li F, Harmer P, Cardinal BJ, Bosworth M, Johnson-Shelton D, Moore JM, Acock A, Vongjaturapat N. 2009. Built environment and 1-year change in weight and waist circumference in middle-aged and older adults. Portland Neighborhood Environment and Health Study. Am J Epidemiol 169: 401-408.

5) Morland KB, Evenson KR. 2009. Obesity prevalence and the local food environment. Health Place 15: 491495.

6) Li F, Harmer P, Cardinal BJ, Bosworth M, Johnson-Shelton D. 2009. Obesity and the built environment: does the density of neighborhood fast-food outlets matter? Am J Health Promot 23: 203-209.

7) Jeffery RW, Baxter J, McGuire M, Linde J. 2006. Are fast food restaurants an environmental risk factor for obesity? Int J Behav Nutr Phys Act 3: 2.

8) Morland K, Wing S, Diez Roux A. 2002. The contextual effect of the local food environment on residents' diets: the atherosclerosis risk in communities study. Am J Public Health 92: 1761-1767.

9) Pearce J, Hiscock R, Blakely T, Witten K. 2009. A national study of the association between neighbourhood access to fast-food outlets and the diet and weight of local residents. Health Place 15: 193-197.

10) Crawford DA, Timperio AF, Salmon JA, Baur L, GilesCorti B, Roberts RJ, Jackson ML, Andrianopoulos N, Ball K. 2008. Neighbourhood fast food outlets and obesity in children and adults: the CLAN Study. Int J Pediatr Obes 3: $249-256$.

11) Thornton LE, Bentley RJ, Kavanagh AM. 2009. Fast food purchasing and access to fast food restaurants: a multilevel analysis of VicLANES. Int J Behav Nutr Phys Act 6: 28 .

12) Sasaki S, Yanagibori R, Amano K. 1998. Self-administered diet history questionnaire developed for health education: a relative validation of the test-version by comparison with 3-day diet record in women. J Epidemiol 8: 203-215. 
13) Sasaki S, Yanagibori R, Amano K. 1998. Validity of a self-administered diet history questionnaire for assessment of sodium and potassium: comparison with single 24-hour urinary excretion. Jpn Circ J 62: 431-435.

14) Sasaki S, Ushio F, Amano K, Morihara M, Todoriki T, Uehara Y, Toyooka T. 2000. Serum biomarker-based validation of a self-administered diet history questionnaire for Japanese subjects. I Nutr Sci Vitaminol 46: 285-296.

15) Murakami K, Sasaki S, Takahashi Y, Okubo H, Hirota N, Notsu A, Fukui M, Date C. 2008. Reproducibility and relative validity of dietary glycaemic index and load assessed with a self-administered diet-history questionnaire in Japanese adults. Br J Nutr 99: 639-648.

16) Ministry of Health, Labour and Welfare of Japan. 2008. The National Health and Nutrition Survey in Japan, 2005. Daiichi Shuppan Publishing, Tokyo (in Japanese).

17) Ministry of Economy, Trade and Industry, Japan. 2008. Census of Commerce 2002 by Grid Square System. Research Institute of Economy, Trade and Industry, Tokyo (in Japanese).

18) Murakami K, Sasaki S, Takahashi Y, Uenishi K. 2007. Dietary energy density is associated with body mass index and waist circumference, but not with other metabolic risk factors, in free-living young Japanese women. Nutrition 23: 798-806.

19) Murakami K, Sasaki S, Takahashi Y, Uenishi K. 2008. Association between dietary acid-base load and cardiometabolic risk factors in young Japanese women. $\mathrm{Br} J$ Nutr 100: 642-651.

20) Murakami K, Sasaki S, Takahashi Y, Uenishi K. 2008. Intake of water from foods, but not water from beverages, is related to lower body mass index and waist circumference in free-living humans. Nutrition 24: 925932.

21) Statistics Bureau, Ministry of Internal Affairs and Communications, Japan. 2010. E-Stat. Statistics Bureau, Ministry of Internal Affairs and Communications, Japan. [Online]. Available: http://www.e-stat.go.jp/SG1/estat/ eStatTopPortal.do [accessed March 5, 2010] (in Japanese).

22) Science and Technology Agency. 2005. Standard Tables of Food Composition in Japan, 5th ed. Printing Bureau of the Ministry of Finance, Tokyo (in Japanese).

23) Murakami K, Sasaki S, Okubo H, Takahashi Y, Hosoi Y, Itabashi M. 2007. Monetary costs of dietary energy reported by young Japanese women: association with food and nutrient intake and body mass index. Public Health Nutr 10: 1430-1439.

24) Murakami K, Sasaki S, Takahashi Y, Uenishi K, Yamasaki M, Hayabuchi H, Goda T, Oka J, Baba K, Ohki K, Kohri T, Watanabe R, Sugiyama Y. 2008. Misreporting of dietary energy, protein, potassium and sodium in relation to body mass index in young Japanese women. Eur J Clin Nutr 62: 111-118.

25) Murakami K, Sasaki S, Takahashi Y, Uenishi K. 2009. Neighborhood food store availability in relation to food intake in young Japanese women. Nutrition 25: 640646.

26) Statistics Bureau, Ministry of Internal Affairs and Communications, Japan. 2009. Japan Standardized Industrial Classification. Statistics Bureau, Ministry of Internal Affairs and Communications, Japan. [Online].
Available: http://www.stat.go.jp/index/seido/sangyo/ pdf/19san1.pdf [accessed August 28, 2009] (in Japanese).

27) Ainsworth BE, Haskell WL, Leon AS, Jacobs DR Jr, Montoye HJ, Sallis JF, Paffenbarger RS Jr. 1993. Compendium of physical activities: classification of energy costs of human physical activities. Med Sci Sports Exerc 25: $71-80$.

28) Murakami K, Sasaki S, Okubo H, Takahashi Y. 2009. Neighborhood socioeconomic status in relation to dietary intake and body mass index in female Japanese dietetic students. Nutrition 25: 745-752.

29) Kant AK, Graubard BI. 2004. Eating out in America, 1987-2000: trends and nutritional correlates. Prev Med 38: 243-249.

30) Orfanos P, Naska A, Trichopoulos D, Slimani N, Ferrari P, van Bakel M, Deharveng G, Overvad K, Tjonneland A, Halkjaer J, de Magistris MS, Tumino R, Pala V, Sacerdote C, Masala G, Skeie G, Engeset D, Lund E, Jakszyn P, Barricarte A, Chirlaque MD, Martinez-Garcia C, Amiano P, Quiros JR, Bingham S, Welch A, Spencer EA, Key TJ, Rohrmann S, Linseisen J, Ray J, Boeing H, Peeters PH, Bueno-de-Mesquita HB, Ocke M, Johansson I, Johansson G, Berglund G, Manjer J, Boutron-Ruault MC, Touvier M, Clavel-Chapelon F, Trichopoulou A. 2007. Eating out of home and its correlates in 10 European countries. The European Prospective Investigation into Cancer and Nutrition (EPIC) study. Public Health Nutr 10: 1515-1525.

31) French SA, Harnack L, Jeffery RW. 2000. Fast food restaurant use among women in the Pound of Prevention study: dietary, behavioral and demographic correlates. Int J Obes Relat Metab Disord 24: 1353-1359.

32) Burns C, Jackson M, Gibbons C, Stoney RM. 2002. Foods prepared outside the home: association with selected nutrients and body mass index in adult Australians. Public Health Nutr 5: 441-448.

33) Bezerra IN, Sichieri R. 2009. Eating out of home and obesity: a Brazilian nationwide survey. Public Health Nutr 12: 2037-2043.

34) Duffey KJ, Gordon-Larsen P, Jacobs DR Jr, Williams OD, Popkin BM. 2007. Differential associations of fast food and restaurant food consumption with 3-y change in body mass index: the Coronary Artery Risk Development in Young Adults Study. Am J Clin Nutr 85: 201208.

35) McCrory MA, Fuss PJ, Hays NP, Vinken AG, Greenberg AS, Roberts SB. 1999. Overeating in America: association between restaurant food consumption and body fatness in healthy adult men and women ages 19 to 80 . Obes Res 7: 564-571.

36) Timperio AF, Ball K, Roberts R, Andrianopoulos N, Crawford DA. 2009. Children's takeaway and fast-food intakes: associations with the neighbourhood food environment. Public Health Nutr 12: 1960-1964.

37) Pickett KE, Kelly S, Brunner E, Lobstein T, Wilkinson RG. 2005. Wider income gaps, wider waistbands? An ecological study of obesity and income inequality. J Epidemiol Commun Health 59: 670-674.

38) Wang MC, Gonzalez AA, Ritchie LD, Winkleby MA. 2006. The neighborhood food environment: sources of historical data on retail food stores. Int J Behav Nutr Phys Act 3: 15. 